\title{
Single pretreatment of remifentanil may reduce pain after propofol and rocuronium injection in rapid sequence induction
}

\author{
Yoon Ji Choi ${ }^{1}$, Han Seok Park ${ }^{2}$, Han Lee ${ }^{3}$, and Seung Zhoo Yoon ${ }^{3}$ \\ ${ }^{1}$ Department of Anesthesiology and Pain Medicine, Asan Medical Center, ${ }^{2}$ Aju Pyeonhan Pain Clinic, ${ }^{3}$ Department of Anesthesiology \\ and Pain Medicine, Anam Hospital, Korea University, Seoul, Korea
}

Background: We designed this double-blind, placebo-controlled study to compare the efficacy of remifentanil in reducing the pain of both propofol and rocuronium injection during rapid-sequence induction.

Methods: Ninety-five patients, scheduled for elective surgery under general anesthesia, were divided into 3 groups: saline (Group S, $\mathrm{n}=31$ ), remifentanil $1 \mu \mathrm{g} / \mathrm{kg}$ (Group R, $\mathrm{n}=32$ ), and lidocaine $1.5 \mathrm{mg} / \mathrm{kg}$ (Group L, $\mathrm{n}=32$ ) were administered after tourniquet application. The occlusion was released after $1 \mathrm{~min}$ and $5 \mathrm{ml}$ of $1 \%$ propofol was injected over $10 \mathrm{~s}$. Pain on propofol injection was evaluated by a 10-point verbal numeric rating scale (VNRS). The rest of the induction dose of propofol and $1 \mathrm{mg} / \mathrm{kg}$ of rocuronium, were injected. Pain on rocuronium injection was evaluated by a four-point score (FPS).

Results: The VNRS of propofol injection was as follows: R $(0.78)=\mathrm{L}(1.34)<\mathrm{S}(4.26)$. The incidence of withdrawal response due to rocuronium was as follows: $\mathrm{R}(6.3 \%)<\mathrm{L}(53.1 \%)<\mathrm{S}(83.9 \%)$. The FPS of rocuronium injection was as follows: $\mathrm{R}(0.81)<\mathrm{L}(1.78)<\mathrm{S}(2.93)$.

Conclusions: Pretreatment with a bolus of remifentanil was effective in simultaneously reducing injection pain of propofol and rocuronium. In addition, remifentanil pretreatment was more effective in suppression of withdrawal response by rocuronium than lidocaine. (Korean J Anesthesiol 2012; 63: 413-418)

Key Words: Injection pain, Lidocaine, Propofol, Remifentanil, Rocuronium.

Received: March 21, 2012. Revised: 1st, May 9, 2012; 2nd, May 12, 2012. Accepted: May 21, 2012.

Corresponding author: Seung Zhoo Yoon, M.D., Ph.D., Department of Anesthesiology and Pain Medicine, College of Medicine, Korea University, 5, Anam-dong, Sungbuk-gu, Seoul 136-705, Korea. Tel: 82-2-920-5632, Fax: 82-2-929-2936, E-mail: monday1031@yahoo.co.kr (c) This is an open-access article distributed under the terms of the Creative Commons Attribution Non-Commercial License (http:// creativecommons.org/licenses/by-nc/3.0/), which permits unrestricted non-commercial use, distribution, and reproduction in any medium, provided the original work is properly cited. 


\section{Introduction}

Propofol and rocuronium are preferred induction anesthetic and muscle relaxant for their properties of both a fast onset and a rapid recovery profile. When a bolus of large amount (more than $0.9 \mathrm{mg} / \mathrm{kg}$ ) is used, rocuronium can induce muscle relaxation within one minute, and is an attractive alternative to succinylcholine. Therefore, propofol and rocuronium have often been paired in rapid-sequence anesthesia induction. However, injection pain by both drugs may hamper the use of these drugs together in clinical practice [1]. In addition, the withdrawal response due to injection pain may make rocuronium a secondary choice to succinylcholine in rapid sequence intubation [2].

The concept of suppressing the injection pain of both drugs simultaneously with a single pretreatment may be promising in that the injection pains of propofol and rocuronium can be blunted or abolished by similar pretreatments, such as lidocaine $[3,4]$, opioid $[5,6]$, metoclopramide $[7,8]$, magnesium sulphate $[9,10]$, or ketamine $[11,12]$. Accordingly, there are already a few trials of simultaneous suppression of injection pain from both drugs with a single pretreatment. To our disappointment, the trials showed partial effectiveness in simultaneous suppression of pain on injection of propofol and rocuronium. Reddy et al. [13] reported that ondansetron is effective in relieving the pain of propofol and rocuronium, but is not as effective as lidocaine. In addition, single pretreatment with dexmedetomidine is not effective in reducing the injection pain of propofol, but may attenuate the hand withdrawal associated with rocuronium [14]. Therefore, until now, there has been no drug proven to be effective in suppressing the injection pain of a simultaneous propofol and rocuronium.

The exact pathophysiologic mechanism of pain due to propofol and rocuronium injection is not clearly established. Suppression of injection pain from propofol and rocuronium with a single treatment seems to need 2 different mechanisms. In this regards, remifentanil may be a candidate for pretreatment because remifentanil interacts with peripheral and central $\mu$-opioid receptors [15]. Thus, we designed this double-blind, placebo-controlled study to compare the efficacy of remifentanil in reducing the pain of both propofol and rocuronium injection during rapid sequence induction.

\section{Materials and Methods}

After obtaining approval from the Institutional Review Board and written informed consent, we studied 95 American Society of Anesthesiologists physical status I-II patients, aged 18-60 years, who were presenting for elective surgery that required endotracheal intubation. Patients with known allergy to propofol, rocuronium, lidocaine, or remifentanil, or who had a neuromuscular disorder or cognitive impairment were excluded from this study. Patients were randomly assigned according to a computer generated random number sequence into one of 3 groups, to receive the following study drug in a double-blind manner: saline (Group S, $\mathrm{n}=31$ ), remifentanil $1 \mu \mathrm{g} / \mathrm{kg}$ (Group $\mathrm{R}, \mathrm{n}=32$ ), lidocaine $1.5 \mathrm{mg} / \mathrm{kg}$ (Group $\mathrm{L}, \mathrm{n}=32$ ). Each syringe volume was made up to $6 \mathrm{ml}$ with normal saline, lidocaine, or remifentanil. All treatments were prepared by an independent anesthetist and the investigators were blinded to drug identity.

No premedication was administered before surgery. Upon arrival in the operating room, patients were instructed to inform the investigator about the amount of pain they experienced by use of a 10-point verbal numeric rating scale (VNRS). A 20-G intravenous cannula was placed in the dorsum of the hand for administration of study drug. Non-invasive arterial pressure, pulse oxymeter, electrocardiogram, and train-of-four were monitored. After 3 minutes of preoxygenation, an elastic tourniquet, $2.2 \mathrm{~cm}$ in width, which is normally used in our hospital to assist intravenous cannulation, was applied to the patient's mid forearm. To ensure standardized venous occlusion, an elastic tourniquet was used as the pressure of stopping IV infusion. The study drug was then administered over 10 seconds. One minute after the administration of the study drug, the tourniquet was removed and $5 \mathrm{ml}$ of $1 \%$ propofol (Fresofol ${ }^{\circledR}$, Fresinus Kabi, Austria) was injected over 20 seconds.

The patients were observed and asked immediately if they had pain in the arm, and their responses were assessed by VNRS $[14,16]$. Then, the rest of the induction dose of propofol (total dose $2 \mathrm{mg} / \mathrm{kg}$ ) was injected over 10 seconds. After consciousness was lost, rocuronium $1 \mathrm{mg} / \mathrm{kg}$ was given over 10 seconds. The response of the patients to the injection of rocuronium was assessed with a four-point scale (FPS) by an independent observer. The score was graded as 0 for no response, 1 for movement at the wrist only, 2 for movement involving the arm only (elbow or shoulder), and 3 for generalized response or movement in more than one extremity and reactions such as discomfort or pain (Table 1). We considered that withdrawal movement had occurred when the FPS was over 1.

To estimate the sample size, a power analysis revealed

Table 1. Assessment of Withdrawal Movements of Rocuronium

\begin{tabular}{cl}
\hline $\begin{array}{c}\text { Withdrawal } \\
\text { score }\end{array}$ & Response \\
\hline 0 & No response \\
1 & Movement at the wrist only \\
2 & Movement involving the arm only (elbow or shoulder) \\
3 & Generalized response or movement in more than one \\
& extremity, and reactions such as discomfort or pain \\
\hline
\end{tabular}


that 29 patients in each of the 2 groups were required to be included to detect a $30 \%$ intergroup difference in VNRS of propofol injection pain, at a power of 0.8 , an $\alpha=0.05$, and a SD of the underlying population of 0.6 (obtained from preliminary results). The results were analyzed with one way ANOVA and Bonferroni's post hoc test for age, body weight, height, VNRS, and FPS. The occurrences of withdrawal movements and gender were analyzed by the $\chi^{2}$-test. A P value of $<0.05$ was considered to be statistically significant.

\section{Results}

All 95 patients completed the study. One patient was excluded from this study, because the patients did not want to proceed in the study due to anxiety. There were no major differences between the 3 groups in terms of age, body weight, height, and gender distribution (Table 2).

All 95 of patients expressed the pain of propofol using NVRS. The mean VNRS of Group S, Group L, and Group R were 4.26, 1.34, and 0.78 , respectively. The mean VNRS of Group $S$ was higher than Group R and Group L ( $<<0.05)$. However, the mean VNRS of Group R was not different from Group L (Fig. 1).

Table 2. Patient Characteristics

\begin{tabular}{lccc}
\hline & Group S (n=31) & Group R $(\mathrm{n}=32)$ & Group L $(\mathrm{n}=32)$ \\
\hline Age (yr) & $39.4 \pm 12.4$ & $42.7 \pm 9.8$ & $43.9 \pm 9.2$ \\
Sex (M/F) & $14 / 17$ & $12 / 20$ & $10 / 22$ \\
Weight (kg) & $63.6 \pm 11.8$ & $61.9 \pm 12.0$ & $62.2 \pm 9.3$ \\
Height (cm) & $164.8 \pm 9.1$ & $162.1 \pm 10.1$ & $162.0 \pm 8.8$ \\
\hline
\end{tabular}

Data presented as mean \pm SD or count. Group S: normal saline, Group $\mathrm{R}$ : remifentanil $1 \mu \mathrm{g} / \mathrm{kg}$, Group L: lidocaine $1.5 \mathrm{mg} / \mathrm{kg}$.

A

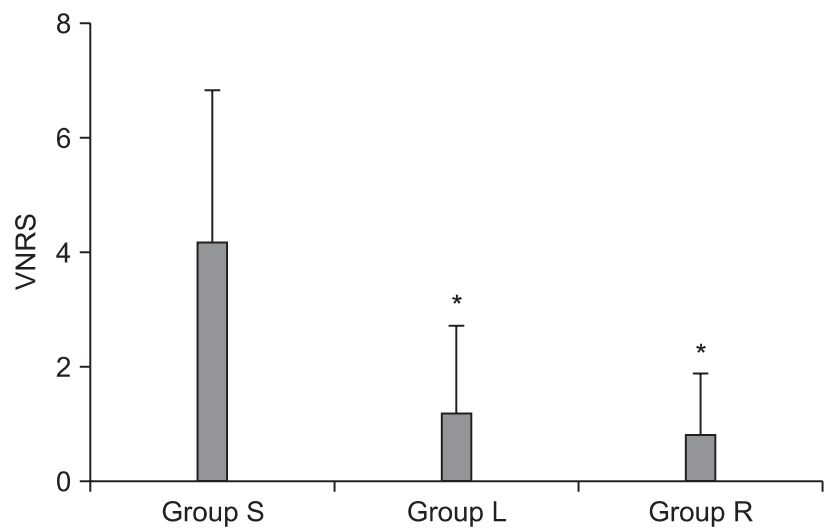

The mean FPS of Group S, Group L, and Group R were 2.93, 1.78, and 0.81 (Fig. 1). The mean FPS of Group $S$ was higher than Group R and Group L $(\mathrm{P}<0.05)$, and the mean FPS of Group L was higher than Group R $(\mathrm{P}<0.05)$. The incidence of withdrawal movements due to rocuronium ( $\geq 1$ response) were as follows: $83.9 \%$ in Group S, 53.1\% in Group L, and 6.3\% in Group R (Fig. 2). The incidence of withdrawal movements due to rocuronium was statistically significantly higher in both Group S and Group L than in Group R. Distribution of FPS of rocuronium injection was demonstrated that the percent of $0,1,2$, and 3 FPS in group S were 16.1, 22.6, 29.1, and 32.3, respectively. Percent of $0,1,2$, and 3 of FPS in group L were $46.9,31.3,15.6$, and 6.3 , respectively, and percent of $0,1,2$, and 3 of FPS in group $\mathrm{R}$ were 93.7, 6.3, 0, and 0, respectively (Fig. 3). Generalized response or movement in more than

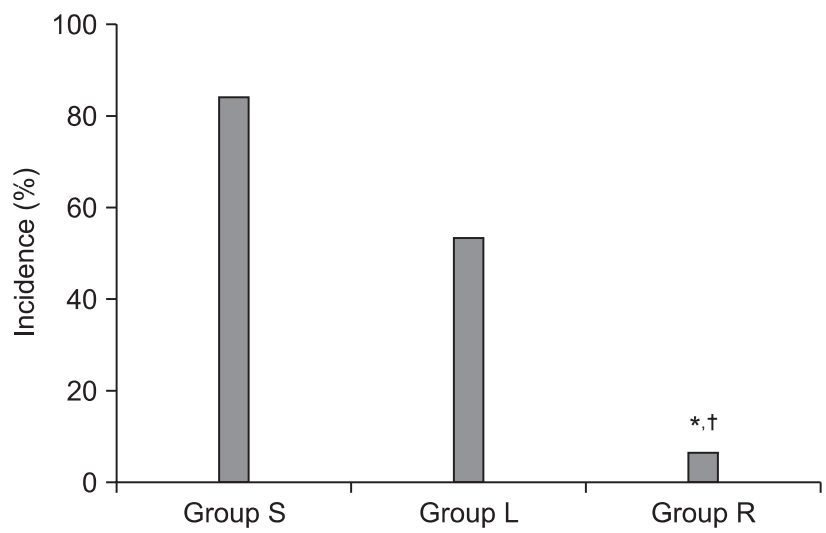

Fig. 2. The incidence of withdrawal movements due to rocuronium ( $\geq 1$ response). Data are presented as percent. Group S: normal saline, Group R: remifentanil $1 \mu \mathrm{g} / \mathrm{kg}$, Group L: lidocaine $1.5 \mathrm{mg} / \mathrm{kg}$. *vs Group S, P $<0.05,{ }^{\dagger}$ vs Group L, P $<0.05$.

B

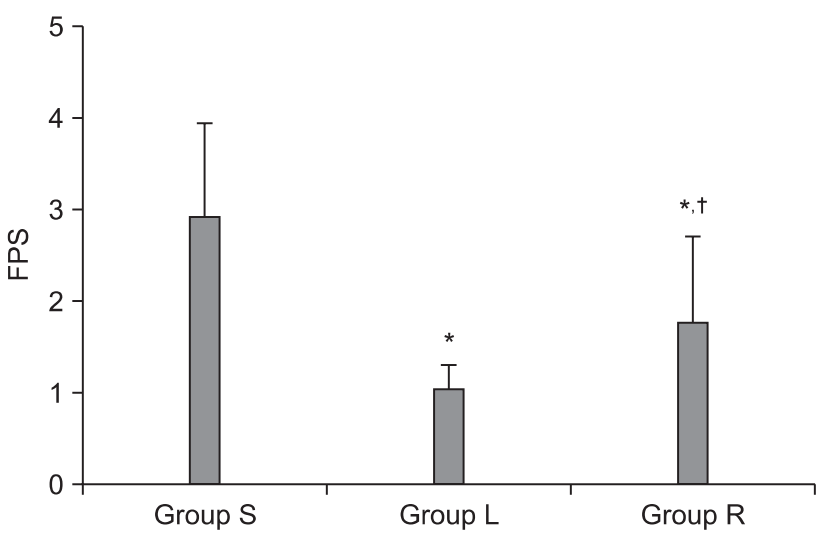

Fig. 1. Injection pain scores of propofol and rocuronium. (A) VNRS, (B) FPS. Data are presented as mean \pm SD. The mean VNRS of Group S was higher than Group R and Group L. VNRS: verbal numeric rating scale, FPS: four-point scale. Group S: normal saline, Group R: remifentanil 1 $\mu \mathrm{g} / \mathrm{kg}$, Group L: lidocaine $1.5 \mathrm{mg} / \mathrm{kg}$. *vs Group S, P $<0.05,{ }^{\dagger}$ vs Group L, P $<0.05$. 
A

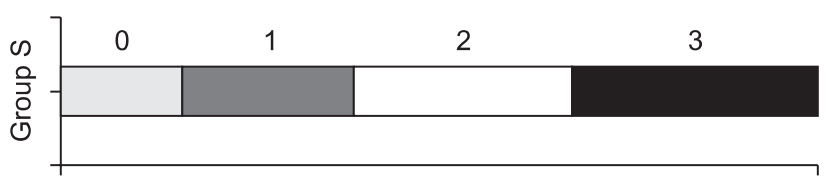

FPS

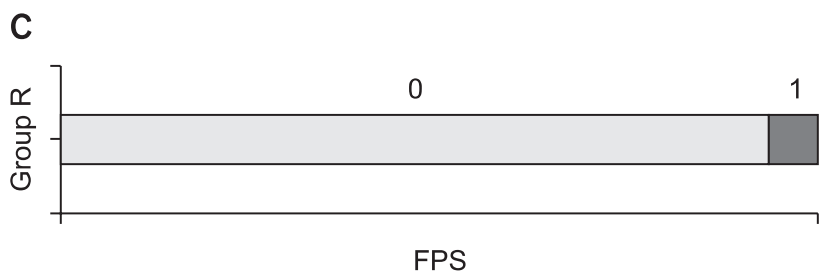

B

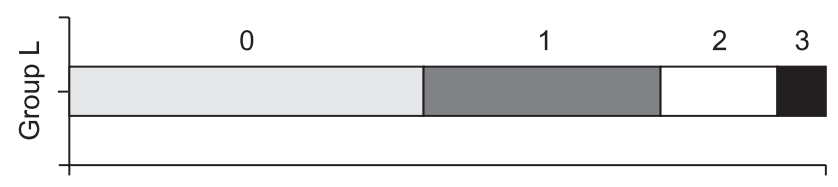

FPS

Fig. 3. Distribution of FPS of rocuronium injection. (A) Group S, (B) Group L, (C) Group R. Data are presented as percent. Group S: normal saline, Group R: remifentanil $1 \mu \mathrm{g} / \mathrm{kg}$, Group L: lidocaine $1.5 \mathrm{mg} / \mathrm{kg}$. FPS: four-point scale.

one extremity, and reactions such as discomfort or pain was the most frequent response to rocuronium injection in group $\mathrm{S}$, whereas movement at the wrist only is the most frequent response of rocuronium injection in group $\mathrm{R}$.

\section{Discussion}

To our knowledge, our study is the first trial showed that a single pharmacologic pretreatment may be effective in simultaneous suppression of injection pain from injection of both propofol and rocuronium. Our results revealed that single pretreatment with remifentanil was effective in reducing both injection pain of propofol and rocuronium. However, a pretreatment of lidocaine was not effective in terms of suppressing withdrawal movement due to rocuronium injection.

Propofol can irritate the skin, venous intima, and mucous membrane [17], and may activate the kallikrein-kinin system that plays a role in inflammation, blood pressure control, coagulation, and pain. Propofol, therefore, seems to be related to release of bradykinin, histamine, and other substances mediating inflammation. These produce venous dilation and hyperpermeability that increases the contact between the free form of propofol in the blood and peripheral nerve endings, resulting in pain on injection $[3,5,18]$. In addition, pain-induced movement immediately appears after injection, and arm movement usually presented after the drug administration, and thereby direct irritation of peripheral veins is strongly suspected. Therefore, previous reports have suggested that application of a tourniquet on the arm before propofol injection, in order to keep the drug within the vein [19]. In addition, this study evaluated the effect of lidocaine or remifentanil on the pain of propofol injection using a tourniquet technique. Tourniquet technique allows more time to contact sensory endings with lidocaine, and propofol-induced pain is masked by lidocaine effect as a local anesthetic on the vessel. Lai et al. [20] revealed that $2 \%$ lidocaine works on both nerve trunks and nerve endings. Furthermore, lidocaine seems to act as a buffer to prevent direct contact between the peripheral vessel and propofol $[21,22]$. Nathanson et al. [5] reported that both 40 mg lidocaine and $1 \mathrm{mg}$ alfentanil had equal effect on reducing propofol-induced pain. We showed that lidocaine has a similar effect to remifentanil for propofol injection pain.

The pathophysiologic mechanisms of pain on rocuronium injection include direct activation of C-nociceptors by the nonphysiologic osmolality or $\mathrm{pH} 4$ of the solution and release of endogenous mediators, such as bradykinin and histamine $[22,23]$. All of the following have been used for alleviation of the pain and withdrawal movements caused by rocuronium injection: tramadol [6], midazolam, fentanyl [1,6,24], alfentanil [10,24], remifentanil [24,25], dexmedetomidine [26], ondansetron [6], lidocaine [4,6], ketamine [27], magnesium sulphate [10], dilution of rocuronium with $0.9 \% \mathrm{NaCl}$ [28], and $\mathrm{NaHCO}_{3}$ [10]. Cheong and Wong [4] suggested that $30 \mathrm{mg}$ of lidocaine was more effective to decrease the incidence and severity of rocuronium induced pain than $10 \mathrm{mg}$ of lidocaine. Reddy et al. [13] showed that patients receiving $50 \mathrm{mg}$ of lidocaine had a statistically significant decrease in pain from injection of rocuronium during forearm elastic tourniquet. In this study, we used the higher dose of lidocaine $(1.5 \mathrm{mg} / \mathrm{kg})$ to prevent propofol or rocuronium induced pain. Nevertheless, lidocaine did not alleviate rocuronium induced pain, as much as remifentanil. One important thing was the timing difference between the injection of lidocaine and rocuronium (more than $90 \mathrm{~s}$ in our study vs $10 \mathrm{~s}$ in Cheong and Wong [4] and $60 \mathrm{~s}$ in Reddy et al. [13]). This different finding explained that lidocaine may have a short duration in peripheral analgesic effect and did not last more than $90 \mathrm{~s}$ in our study. Therefore, lidocaine must be 
used immediately before injection of rocuronium. Therefore, lidocaine may not be appropriate for dual suppression.

Remifentanil works on the opioid receptors that are found in the central terminals of primary afferent nerves and the dorsal root ganglia, and in peripheral sensory nerve fibers and terminals [29]. The interaction of remifentanil with peripheral and central $\mu$-opioid receptors, such as fentanyl that has a local anesthetic effect on nerves [15], might alleviate the injection pain on the anesthetic drugs. In the previous studies, remifentanil administration was reported to be as effective as lidocaine. Furthermore, pretreatment of remifentanil is likely to make a deeper level of anesthesia that augments the pain threshold. However, Ahmad et al. [1] suggested that opioid only needs an adequate time for the onset of analgesia. In addition, Roehm et al. [30] reported that remifentanil infusion needs $60 \mathrm{~s}$ to prevent propofol-induced injection pain. Moreover, Memis et al. [6] used the method that the study drug was given after 20 $s$ tourniquet application to the forearm. In this regard, fentanyl might not be effective compared to the efficacy of lidocaine, because there was insufficient time for the onset of the analgesic effect of fentanyl. In this study, propofol was administered 60 $s$ after remifentanil infusion with the tourniquet technique; thus, the peripheral effect of remifentanil with the tourniquet technique is good enough to reduce propofol induced pain.

Previous studies have suggested that ondansetron is not as effective as lidocaine in alleviating the pain of propofol and rocuronium [13]. And, single pretreatment with dexmedetomidine is not effective in decreasing propofol induced injection pain, and may attenuate the hand or arm withdrawal movement associated with rocuronium induced pain [14]. On the other hand, our result showed that pretreatment with a bolus of remifentanil was effective in simultaneously reducing injection pain of propofol and rocuronium. In addition, remifentanil pretreatment was more effective in suppression of withdrawal response by rocuronium than lidocaine.

In conclusion, single pretreatment of remifentanil can be used to control pain effectively after propofol and rocuronium injection in rapid sequence induction.

\section{References}

1. Ahmad N, Choy CY, Aris EA, Balan S. Preventing the withdrawal response associated with rocuronium injection: a comparison of fentanyl with lidocaine. Anesth Analg 2005; 100: 987-90.

2. Mazurek AJ, Rae B, Hann S, Kim JI, Castro B, Cote CJ. Rocuronium versus succinylcholine: are they equally effective during rapidsequence induction of anesthesia? Anesth Analg 1998; 87: 1259-62.

3. Scott RP, Saunders DA, Norman J. Propofol: clinical strategies for preventing the pain of injection. Anaesthesia 1988; 43: 492-4.

4. Cheong KF, Wong WH. Pain on injection of rocuronium: influence of two doses of lidocaine pretreatment. Br J Anaesth 2000; 84: 106-7.
5. Nathanson MH, Gajraj NM, Russell JA. Prevention of pain on injection of propofol: a comparison of lidocaine with alfentanil. Anesth Analg 1996; 82: 469-71.

6. Memis D, Turan A, Karamanlioglu B, Sut N, Pamukcu Z. The prevention of pain from injection of rocuronium by ondansetron, lidocaine, tramadol, and fentanyl. Anesth Analg 2002; 94: 1517-20.

7. Ganta R, Fee JP. Pain on injection of propofol: comparison of lignocaine with metoclopramide. Br J Anaesth 1992; 69: 316-7.

8. Ramaswamy S, Bapna JS. Analgesic effect of metoclopramide and its mechanism. Life Sci 1986; 38: 1289-92.

9. Agarwal A, Dhiraj S, Raza M, Pandey R, Pandey CK, Singh PK, et al. Vein pretreatment with magnesium sulfate to prevent pain on injection of propofol is not justified. Can J Anaesth 2004; 51: 130-3.

10. Turan A, Memis D, Karamanlioglu B, Sut N, Pamukcu Z. The prevention of pain from injection of rocuronium by magnesium sulphate, lignocaine, sodium bicarbonate and alfentanil. Anaesth Intensive Care 2003; 31: 277-81.

11. Tan CH, Onsiong MK, Kua SW. The effect of ketamine pretreatment on propofol injection pain in 100 women. Anaesthesia 1998; 53: 302-5.

12. Mahajan R, Batra YK, Kumar S. Pain on injection of rocuronium: influence of ketamine pretreatment. Can J Anaesth 2005; 52: 111-2.

13. Reddy MS, Chen FG, Ng HP. Effect of ondansetron pretreatment on pain after rocuronium and propofol injection: a randomised, double-blind controlled comparison with lidocaine. Anaesthesia 2001; 56: 902-5.

14. Ayoglu H, Altunkaya H, Ozer Y, Yapakci O, Cukdar G, Ozkocak I. Does dexmedetomidine reduce the injection pain due to propofol and rocuronium? Eur J Anaesthesiol 2007; 24: 541-5.

15. Power I, Brown DT, Wildsmith JA. The effect of fentanyl, meperidine and diamorphine on nerve conduction in vitro. Reg Anesth 1991; 16: 204-8.

16. Hwang I, Noh JI, Kim SI, Kim MG, Park SY, Kim SH, et al. Prevention of pain with the injection of microemulsion propofol: a comparison of a combination of lidocaine and ketamine with lidocaine or ketamine alone. Korean J Anesthesiol 2010; 59: 233-7.

17. Ambesh SP, Dubey PK, Sinha PK. Ondansetron pretreatment to alleviate pain on propofol injection: a randomized, controlled, double-blinded study. Anesth Analg 1999; 89: 197-9.

18. Coderre TJ, Katz J, Vaccarino AL, Melzack R. Contribution of central neuroplasticity to pathological pain: review of clinical and experimental evidence. Pain 1993; 52: 259-85.

19. Borgeat A, Kwiatkowski D, Ruetsch YA. Spontaneous movements associated with rocuronium injection: the effects of prior administration of fentanyl. J Clin Anesth 1997; 9: 650-2.

20. Lai YY, Chang CL, Yeh FC. The site of action of lidocaine in intravenous regional anesthesia. Ma Zui Xue Za Zhi 1993; 31: 31-4.

21. Eriksson M, Englesson S, Niklasson F, Hartvig P. Effect of lignocaine and $\mathrm{pH}$ on propofol-induced pain. Br J Anaesth 1997; 78: 502-6.

22. Klement W, Arndt JO. Pain on i.v. injection of some anaesthetic agents is evoked by the unphysiological osmolality or $\mathrm{pH}$ of their formulations. Br J Anaesth 1991; 66: 189-95.

23. Lockey D, Coleman P. Pain during injection of rocuronium bromide. Anaesthesia 1995; 50: 474.

24. Oh AY, Seo KS, Goo EK, Park YO, Kim SJ, Kim JH. Prevention of withdrawal movement associated with injection of rocuronium in 
children: comparison of remifentanil, alfentanil and fentanyl. Acta Anaesthesiol Scand 2007; 51: 1190-3.

25. Kim JY, Kim JY, Kim YB, Kwak HJ. Pretreatment with remifentanil to prevent withdrawal after rocuronium in children. Br J Anaesth 2007; 98: 120-3.

26. Memis D, Turan A, Kaya G, Karamanlioglu B, Seker S. Preventing pain on injection of rocuronium: two doses of dexmedetomidine. Can J Anaesth 2005; 52: 437-8.

27. Liou JT, Hsu JC, Liu FC, Ching-Wah Sum D, Lui PW. Pretreatment with small-dose ketamine reduces withdrawal movements associated with injection of rocuronium in pediatric patients. Anesth
Analg 2003; 97: 1294-7.

28. Tuncali B, Karci A, Tuncali BE, Mavioglu O, Olguner CG, Ayhan S, et al. Dilution of rocuronium to $0.5 \mathrm{mg} / \mathrm{ml}$ with $0.9 \% \mathrm{NaCl}$ eliminates the pain during intravenous injection in awake patients. Anesth Analg 2004; 99: 740-3.

29. Fields HL, Emson PC, Leigh BK, Gilbert RF, Iversen LL. Multiple opiate receptor sites on primary afferent fibres. Nature 1980; 284: 351-3.

30. Roehm KD, Piper SN, Maleck WH, Boldt J. Prevention of propofolinduced injection pain by remifentanil: a placebo-controlled comparison with lidocaine. Anaesthesia 2003; 58: 165-70. 